\title{
Canine pseudopregnancy: an evaluation of prevalence and current treatment protocols in the UK
}

Amanda L. Root ${ }^{1 *}$, Tim D. Parkin ${ }^{1}$, Pippa Hutchison ${ }^{1}$, Caroline Warnes ${ }^{2}$ and Philippa S. Yam

\begin{abstract}
Background: There is a dearth of literature on pseudopregnancy in the bitch, with only a few treatment-based studies published since the 1990s. Pseudopregnancy may be under-recognised in bitches and may account for a proportion of behavioural cases seen in veterinary practices including aggression. Little is known about commonly used treatments for overtly pseudopregnant bitches and it is possible that current regimes may not be prescribed for a sufficient duration to control any clinical signs including, physical and behavioural changes. To investigate current trends in diagnosis and treatment of canine pseudopregnancy, a postal survey was sent to 2000 randomly selected veterinary surgeons in UK veterinary practices. The questionnaire queried how often vets recognise cases of pseudopregnancy in spayed and entire bitches, which physical or behavioural signs are commonly recognised for diagnosis, and which management or treatment protocols are used.
\end{abstract}

Results: The response rate was 19.8\% (397/2000). Ninety-six percent of veterinary surgeons reported seeing pseudopregnant bitches showing behavioural changes without any physical changes within the last 12 months. Of those behavioural changes, collecting and mothering objects was the most frequently reported behavioural sign (96\%). Ninety-seven percent of vets had seen aggression in pseudopregnant bitches. Nevertheless, only 52\% of vets routinely asked owners about behavioural changes during consultations. Forty-nine percent of respondents reported seeing pseudopregnancy in spayed bitches. The most commonly reported physical sign was enlarged mammary glands and/or milk production (89\%). Treatment options varied (surgical, medical or none) and depended on duration and severity of physical and behavioural signs, owners' preference, cost, concurrent disease, drug availability and previous history.

Conclusions: This is the largest epidemiological study of canine pseudopregnancy in the UK. The prevalence and severity of clinical signs in dogs with pseudopregnancy are variable and possibly under-estimated. Dogs with overt pseudopregnancy experience diverse physical and behavioural changes and information on standard treatment protocols are lacking. Although, progress on our understanding of diagnosis and treatment of pseudopregnancy in spayed and entire bitches has been made, further studies are warranted.

Keywords: Aggression - behaviour, Bitch - dog, Cabergoline, Epidemiology, Pseudopregnancy, Pseudocyesis, Questionnaire

\footnotetext{
* Correspondence: 2067404r@student.gla.ac.uk

${ }^{1}$ School of Veterinary Medicine, College of Medicine, Veterinary and Life

Sciences, University of Glasgow, 464 Bearsden Road, Glasgow G61 1QH,

Scotland

Full list of author information is available at the end of the article
}

(c) The Author(s). 2018 Open Access This article is distributed under the terms of the Creative Commons Attribution 4.0 International License (http://creativecommons.org/licenses/by/4.0/), which permits unrestricted use, distribution, and reproduction in any medium, provided you give appropriate credit to the original author(s) and the source, provide a link to the Creative Commons license, and indicate if changes were made. The Creative Commons Public Domain Dedication waiver (http://creativecommons.org/publicdomain/zero/1.0/) applies to the data made available in this article, unless otherwise stated. 


\section{Background}

Pseudopregnancy, also known as pseudocyesis is where an entire or spayed bitch shows clinical signs typical of the peri and post-partum period of pregnancy, despite the bitch not being pregnant. Pseudopregnancy can be further classified as overt, which is the clinical condition and covert, which is the normal physiological condition [1-12]. Pseudopregnancy in bitches has physiological and behavioural effects and is characterised by a range of physical and behavioural changes that commonly appear between six to eight weeks after oestrous [1, 2, 11-13]. Affected dogs may experience clinical signs including enlarged mammary glands and/or milk production, weight gain, vomiting, and appetite loss [1, 3-7, 13-17]. Behavioural signs consist of, but are not limited to, maternal behaviours including aggression in defence of resources, increased or reduced activity, nesting behaviour, and collecting or mothering objects [3-7, 13-18]. In some cases, the physical and behavioural signs can be marked.

The precise aetiology of clinical pseudopregnancy is still poorly understood, but is reported to be linked with the exposure and decline of plasma progesterone, high plasma prolactin concentrations, an increased tissue sensitivity to prolactin, or the existence of molecular variants of prolactin with varying bioactivities [3-6, 8, 11-14, 16, 19]. Based on clinical studies on pseudopregnancy in dogs, the estimated incidence of clinical pseudopregnancy can be as high as $50-75 \%$ in certain breeds (e.g. Afghan Hounds, Beagles, Boxers, and Dachshunds) $[4,5,20]$.

Although pseudopregnancy is most commonly recognised in entire bitches, it can also develop as a result of spaying, particularly if susceptible bitches are spayed during dioestrous. Unless the relationship between spaying and the onset of clinical signs is very clear, veterinary surgeons may be less likely to recognise pseudopregnancy in a spayed bitch $[3,6,10,16]$. It may be one cause of the increase in reactivity and/or aggression in bitches after being spayed [16, 21-23]. Aggression, in particular, is a potentially serious behavioural problem, which can result in not only injury to people, but also to dogs being relinquished or euthanised [18, 24, 25] and it is considered the most recurrent complaint in relation to canine behaviour. However, the extent of this as a direct result of pseudopregnancy is not yet known [10, 26-29].

There are currently no specific diagnostic tests for pseudopregnancy since hormonal assays are non-diagnostic for this condition $[1,10-12,16]$. Some dogs may present solely with behavioural signs, therefore a diagnosis of pseudopregnancy can be challenging.

Current epidemiological research literature and clinical trials pertaining to pseudopregnancy in the bitch is scarce, with only a handful of papers published since the late 1990s [13, 15, 16, 23, 30]. Therefore, a retrospective study was designed to advance our understanding of this complex condition. The questionnaire was designed to investigate through anamnesis, the prevalence, diagnosis, and treatment of canine pseudopregnancy in veterinary practices in the UK.

\section{Methods}

The study was undertaken using a questionnaire-based postal study during a three-week period between October-November 2015. The questionnaire was sent to 2000 randomly selected veterinary surgeons that were registered on a market research database of veterinary surgeons (Vetfile), and members of the Royal College of Veterinary Surgeons in the UK in either small or mixed general practice. Referral practitioners, diplomate holders, locums, and veterinary surgeons in academia were excluded from the sample. The specific population sought was general practitioner vets, because they have a higher case load of pseudopregnancy and will be responsible for diagnosing the condition and making decisions about treatment. A prize draw for $£ 300$, postage paid return envelopes, and a summary of the survey results once analysed were offered as incentives for questionnaire completion and return.

\section{Questionnaire design}

A copy of the questionnaire can be viewed in Fig. 1. Various question types, such as Likert-scale, dichotomous, closed-format, and open-format were used to obtain information about pseudopregnancy in canines. The survey included six statements associated with Likert-scale questions that reported on frequency (never, rarely, sometimes, often) and influence (no, some, strong). Additionally, a space for qualitative comments was available for the veterinary surgeons to expand on each of the open-ended questions. The raw data from the questionnaires was manually entered into a standard spreadsheet (comma separated values) file. There were three questions where either 'exact' or 'estimated' information could be given in regard to number of bitches spayed, bitches spayed before their first season, and bitches showing physical and/or behavioural signs of pseudopregnancy in the last 12 months. Supplementary comments on treatment approach were analysed thematically and appropriate larger categories created.

\section{Statistical analysis}

Descriptive statistics were obtained using statistical analysis software (Analysis-Tool Kit for Microsoft Office Excel 2016) on the continuous data. The prevalence of the outcomes measured were estimated, specifically the prevalence of pseudopregnancy and clinical signs (physical or 
SURVEY OF CANINE PSEUDOPREGNANCY - 2015

We are helping to collect information for a research project run by the University of Glasgow, School of Veterinary Medicine. Please spare 5 minutes to complete this questionnaire covering the incidence of pseudopregnancy in entire and spayed bitches. We would like to hear from you even if you rarely see
the condition as it will help us obtain an accurate measurement of the incidence. Your replies are confidential and all completed questionnaires returned to us by 13 November 2015 will be entered in a draw for the chance to win $£ 300$ in cash.
At a later date we will circulate a summary of findings to people who have helped us with the survey.

Q2 Please indicate how often you see the following physical signs in bitches with pseudopregnancy:

$\begin{array}{rcccc}\text { a. Enlarged mammary glands +/- milk production... } & \text { Never } & \text { Rarely } & \text { Sometimes } & \text { Often } \\ \text { b. Weight gain... } & \square & \square & \square & \square \\ \text { c. Vomiting... } & \square & \square & \square & \square \\ \text { d. Appetite loss... } & \square & \square & \square & \square\end{array}$

Q3 Please indicate how often you ask owners about changes in their animal's behaviour during routine consultations:

$$
\begin{array}{cccc}
\text { Never } & \text { Rarely } & \text { Sometimes } & \text { Often } \\
\square & \square & \square & \square
\end{array}
$$

Q4 Please indicate how often the behavioural signs listed below are reported by owners of pseudopregnant bitches:

\begin{tabular}{|c|c|c|c|c|}
\hline \multirow{3}{*}{$\begin{array}{l}\text { a. 'Maternal' aggression (uncharacteristic aggression when } \\
\text { approached or guarding resources e.g. food, toys)... } \\
\text { b. Increased activity: restlessness, agitation, increased } \\
\text { reactivity to stimuli e.g. noises... }\end{array}$} & Never & Rarely & Sometimes & Often \\
\hline & $\square$ & $\square$ & $\square$ & $\square$ \\
\hline & $\square$ & $\square$ & $\square$ & $\square$ \\
\hline $\begin{array}{l}\text { c. Reduced activity: depression, reduced responsiveness to } \\
\text { stimuli... }\end{array}$ & $\square$ & $\square$ & $\square$ & $\square$ \\
\hline d. Nesting behaviour: digging, nest-building... & $\square$ & $\square$ & $\square$ & $\square$ \\
\hline e. Collecting and 'mothering' objects e.g. toys ... & $\square$ & $\square$ & $\square$ & $\square$ \\
\hline
\end{tabular}

Q5 How frequently do you see pseudopregnant bitches showing behaviour changes without any physical changes (such as mammary enlargement or milk production)?

$$
\begin{array}{cccc}
\text { Never } & \text { Rarely } & \text { Sometimes } & \text { Often } \\
\square & \square & \square & \square
\end{array}
$$

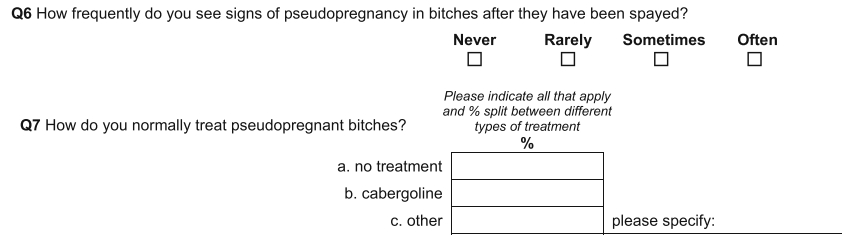

Q8 Does your treatment approach for pseudopregnant bitches differ from one case to another?

$$
\begin{array}{ccc}
\text { Yes ... } & \square & \text { Please answer Q9 } \\
\text { No... } & \square & \text { Please skip to Q10 }
\end{array}
$$

Q9 If your treatment approach differs from one case to another please indicate which of these are most likely to influence your choice:

$$
\begin{aligned}
& \text { Q9 If your treatment approach differs from one case to another please indicate which of these are most likely to influence your choice: } \\
& \text { f. cost .. }
\end{aligned}
$$

$\begin{array}{ccc}\begin{array}{c}\text { No } \\ \text { influence }\end{array} & \begin{array}{c}\text { Some } \\ \text { influence }\end{array} & \begin{array}{c}\text { Strong } \\ \text { influence }\end{array} \\ \square & \square & \square \\ \square & \square & \square \\ \square & \square & \square \\ \square & \square & \square \\ \square & \square & \square \\ \square & \square & \square \\ \square & \square & \square\end{array}$

Q10 If you use cabergoline to treat pseudo pregnant bitches... (if you do not use cabergoline skip to Q11)

$$
\begin{aligned}
& \text { a. how many days of treatment do you normally prescribe? } \\
& \begin{array}{r}
\text { completely resolve physical signs of pseudopregnancy? } \\
\text { if }
\end{array} \\
& \text { days) that has been needed to completely resolve the physical signs? } \\
& \text { d. have you ever needed to give repeated courses of medication in order to days } \\
& \text { if repeated courses haveletely resolve behavioural signs of pseudopregnancy? }
\end{aligned}
$$

Q11 If a bitch was presented for spaying and either showed, or the owner reported that she had physical and/or

behavioural signs of pseudopregnancy would you usually...
a. go ahead and spay her anyway?.

il the physical and behavioural sign

of pseudopregnancy had gone?

c. treat using medication?

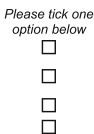

d. other - please specify

Which medication?

Q12 Would you be interested in participating in a prospective study of the incidence of pseudopregnancy in bitches?

$$
\begin{array}{ccc}
\text { Yes ... } & \square & \text { Please give email address below } \\
\text { No... } & \square
\end{array}
$$

Q13 If you are interested in receiving a summary of the results of this survey or in participating in a future study please give your email address (clearly!) below.

Fig. 1 Canine pseudopregnancy postal questionnaire used for study 
behavioural) commonly recognised as part of a diagnosis, and $95 \%$ confidence intervals (CI) were calculated [31]. Contingency table chi-square tests were used to assess associations between categorical variables or to identify differences in proportions with the level of significance set at $p \leq 0.05$. To investigate the prevalence of canine pseudopregnancy, data were divided into categories. For example, the prevalence of pseudopregnancy was stratified by demographics (size, type, and structure of practice, job title and gender of veterinary surgeons, and region), physical signs, behavioural signs, and treatment used. Permission to conduct this study was granted by the University of Glasgow's Research Ethics Committee.

\section{Results}

\section{Demographics and descriptive analysis}

All responses were collected during the three-week period of the survey. No reminders were sent out during that period. There was a response rate of 19.8\% (397/ 2000) to the questionnaire. There were a small number of missing responses to various questions, ranging from 0 to $5 \%$ on any given questionnaire. The retrospective data was taken from the questionnaire responses, which was collected via anamnesis from the owner to veterinary surgeon.

A summary of respondent demographics is presented in Table 1. Thirty-nine percent of respondents (153/397) reported they would be interested in participating in a prospective study.

Table 2 summarises the descriptive statistics. For the three questions ( $1 \mathrm{a}, \mathrm{b}$, and $\mathrm{c}), 84 \%$ of the answers were estimated figures rather than exact. Ninety-seven percent of veterinary surgeons had seen at least one case of pseudopregnancy in the previous 12 months (mean 16; median 10; range 0-250) (Fig. 2).
Forty-two percent $(9744 / 22,986)$ of bitches had been spayed by veterinary surgeons before their first season in the previous 12 months. Forty-nine percent of veterinary surgeons reported seeing pseudopregnancy in spayed bitches, however, of these, only $1 \%$ saw it often, $7 \%$ sometimes and $41 \%$ rarely.

\section{Physical signs and behavioural signs of pseudopregnancy}

The most frequently reported clinical sign of pseudopregnancy was enlarged mammary glands and/or milk production (Fig. 3a), followed by appetite loss (Fig. 3b). Owners rarely reported weight gain (Fig. 3c) or vomiting (Fig. 3d).

The behavioural sign most often seen was collecting and mothering objects (Fig. 4a) followed by nesting behaviour (Fig. 4b), increased activity (Fig. 4c), and reduced activity (Fig. 4d). Ninety-seven percent of vets indicated that they had seen maternal aggression in pseudopregnant bitches (Fig. 4e, 19\% often; 44\% sometimes; 33\% rarely; $3 \%$ never).

Ninety-six percent of veterinary surgeons have seen behavioural changes, without any physical changes, as the main presenting sign for pseudopregnancy within the last 12 months. Of these, $4 \%$ reported this to be often, $41 \%$ sometimes and $50 \%$ rarely (Fig. 4f).

Only $52 \%$ of respondents reported that they often asked owners about behavioural changes during routine consultations (35\% sometimes, $12 \%$ rarely and $1 \%$ never). Furthermore, senior vets $(60 \%, 68 / 113)$ more frequently asked owners about changes in behaviour during routine consultations compared to junior vets $(49 \%, 140 / 284)$.

\section{Treatment approach for pseudopregnancy}

Figure 5 shows the frequency of reported use of different treatment approaches by veterinary surgeons in pseudopregnant bitches. Mean number of responses for no

Table 1 Respondent demographics in postal questionnaire survey of pseudopregnancy in spayed and entire bitches

\begin{tabular}{|c|c|c|c|c|c|c|c|c|c|c|c|c|}
\hline Respondents & Total & $\begin{array}{l}1-4 \\
\text { Vets }\end{array}$ & $\begin{array}{l}>5 \\
\text { Vets }\end{array}$ & $\begin{array}{l}\mathrm{SA}^{\mathrm{a}} \\
\text { Practice }\end{array}$ & $\begin{array}{l}\text { Mixed }^{b} \\
\text { Practice }\end{array}$ & $\begin{array}{l}\text { North \& } \\
\text { West }^{c}\end{array}$ & $\begin{array}{l}\text { South \& } \\
\text { East }^{d}\end{array}$ & Vet Senior ${ }^{\mathrm{e}}$ & Vet Junior ${ }^{f}$ & Private $^{g}$ & Corporate $^{\text {h }}$ & Charity \\
\hline \multirow{2}{*}{$\begin{array}{l}\text { Sample } \\
\text { Mailed }\end{array}$} & 2000 & 960 & 1040 & 1380 & 620 & 1000 & 1000 & 700 & 1300 & 1605 & 336 & 59 \\
\hline & & $48 \%$ & $52 \%$ & $69 \%$ & $31 \%$ & $50 \%$ & $50 \%$ & $35 \%$ & $65 \%$ & $80 \%$ & $17 \%$ & $3 \%$ \\
\hline \multirow{2}{*}{$\begin{array}{l}\text { Sample } \\
\text { Analysed }\end{array}$} & 397 & 196 & 201 & 278 & 118 & 188 & 209 & 113 & 284 & 331 & 60 & 8 \\
\hline & & $49 \%$ & $51 \%$ & $70 \%$ & $30 \%$ & $47 \%$ & $53 \%$ & $28 \%$ & $72 \%$ & $83 \%$ & $15 \%$ & $2 \%$ \\
\hline $\begin{array}{l}\text { Response } \\
\text { Rate }\end{array}$ & $19.8 \%$ & & & & & & & & & & & \\
\hline
\end{tabular}

Small animal

${ }^{\mathrm{b}}$ Small and large animals are seen in the practice

'Region including Scotland, Northern England, Wales, West Midlands, and Northern Ireland

${ }^{\mathrm{d}}$ Region including East Anglia, East Midlands, London, South East England, and South West England

ePrincipal, partner, or buyer

${ }^{\mathrm{f}}$ Assistant or regular locum

${ }^{9}$ Non-commercial veterinary practice that is independently owned

${ }^{\mathrm{h}}$ Commercial veterinary practice or joint venture franchise 


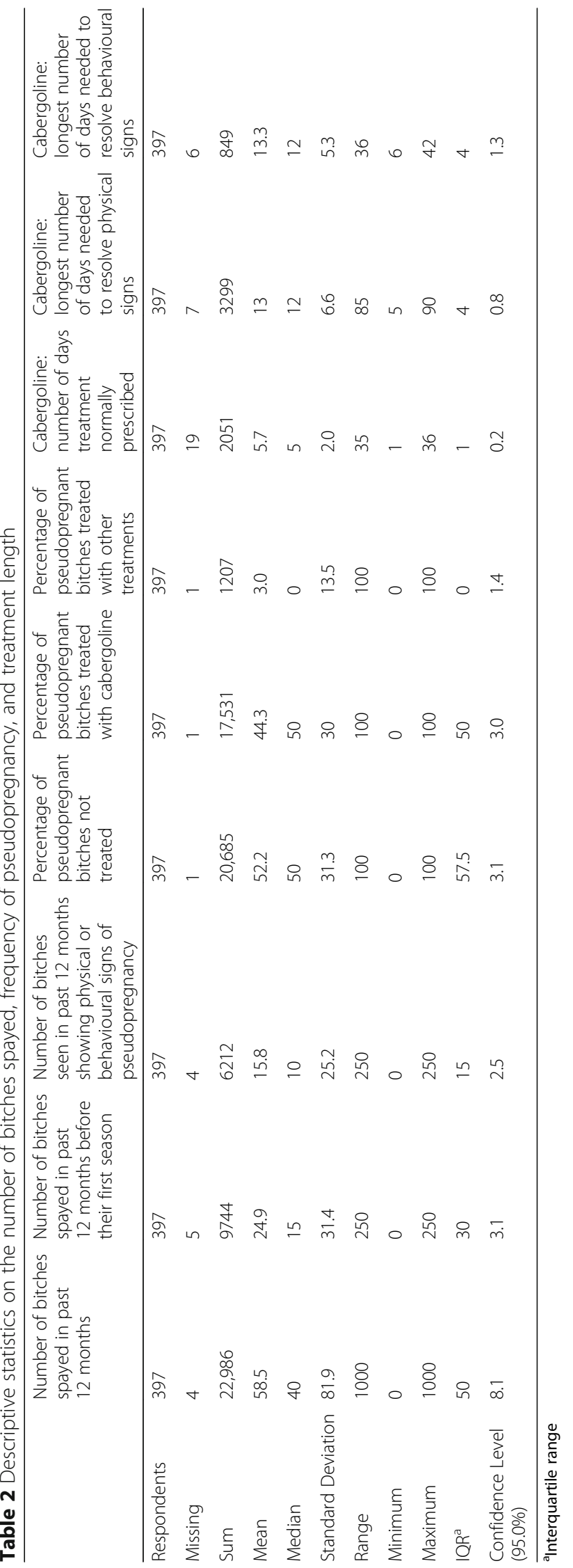




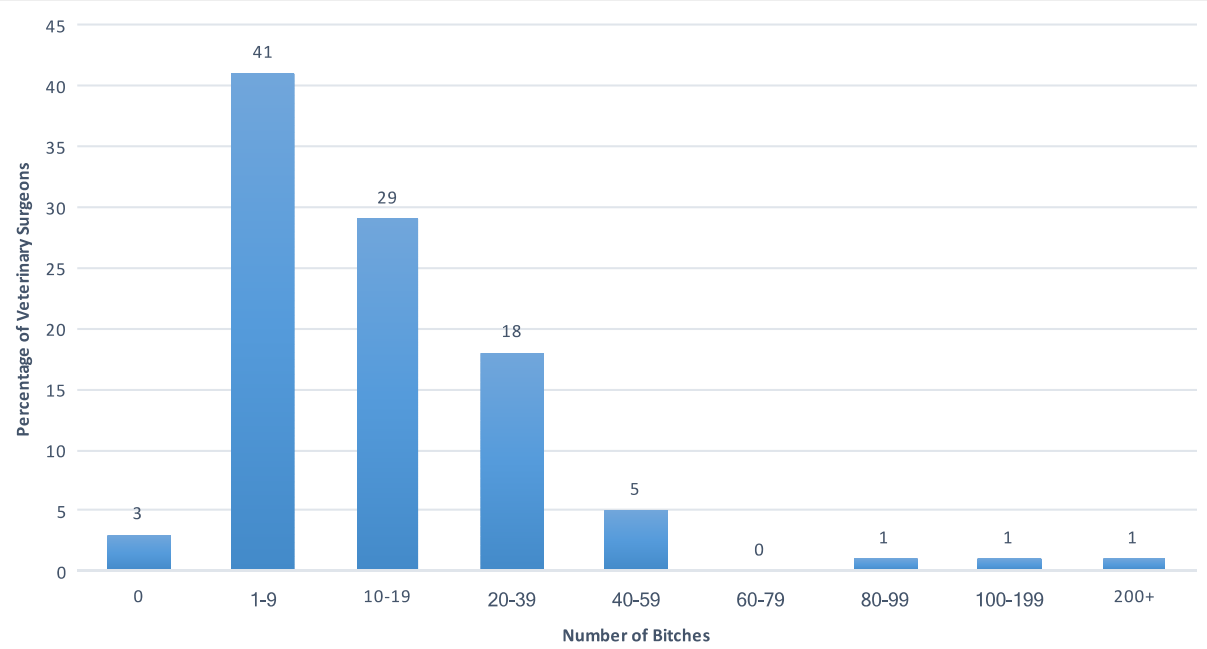

Fig. 2 Number of bitches seen by veterinary surgeons during a 12-month period showing physical and/or behavioural signs of pseudopregnancy

treatment was $52 \%$ (median 50\%), 44\% for cabergoline (Galastop; Ceva, median 50\%), and 3\% for other treatment (median 0\%). For the vets that used cabergoline, the median frequency for which they would use it was $50 \%$ of the time. Most of the responses were in the range of $20-80 \%$ for no treatment. The mean percentage of pseudopregnant bitches not treated was $52 \%$ (median 50\%).
Eighty-eight percent of vets varied their treatment approach for pseudopregnant dogs, junior vets significantly more so than senior vets $(p<0.05)$. Physical signs, behavioural signs, and length of time signs had been present were most likely to influence the treatment choice (Fig. 6). In contrast, factors that only had some influence included owners' preference, potential side effects and cost. a Enlarged mammary glands $+/-$ milk

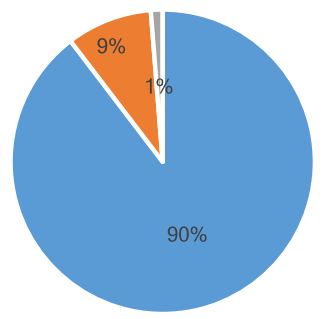

" Often $90 \%$ - Sometimes $9 \% \quad$ "Rarely $1 \% \quad$ " Never $0 \%$

C

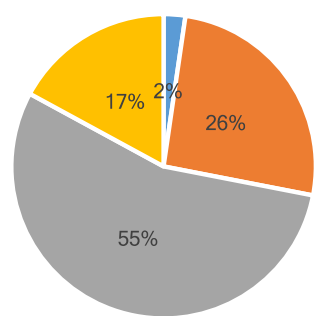

b Appetite loss

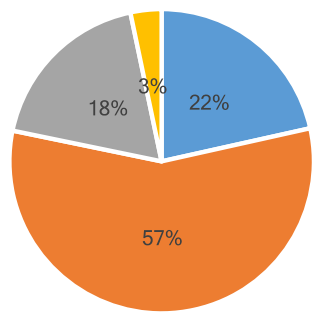

- Often $22 \%$

- Sometimes $57 \%$ - Rarely $18 \%$ "Never $3 \%$

d Vomiting

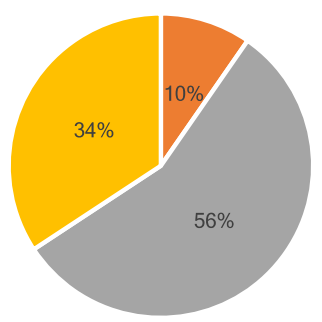

- Often $0 \%$ - Sometimes 10\% " Rarely 56\% " Never 34\%

Fig. 3 Frequency of reported clinical signs of pseudopregnancy in canines. a Enlarged mammary glands +/- milk. b Appetite loss. c Weight gain. d Vomiting 
a Collecting and mothering objects

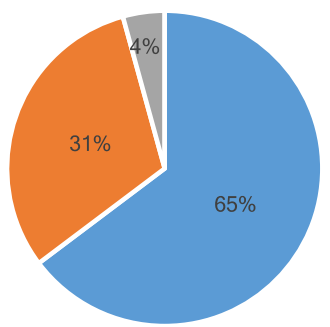

- Often $65 \%$ - Sometimes 31\% - Rarely $4 \%$ - Never $0 \%$

C

Increased activity

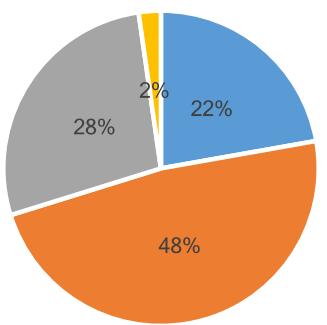

- Often $22 \%$ - Sometimes $48 \%$ - Rarely $28 \%$ - Never $2 \%$

e

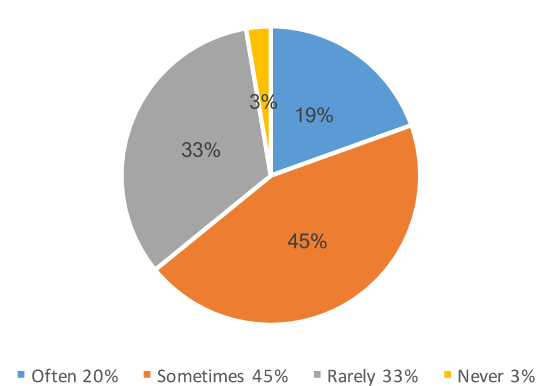

b Nesting behaviour

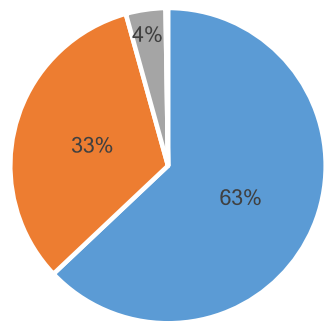

- Often $63 \%$ - Sometimes $33 \%$ - Rarely $4 \% \quad$ - Never $0 \%$

d Reduced activity

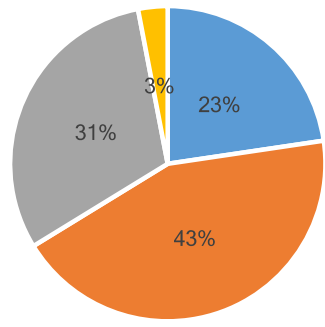

- Often 23\% - Sometimes 43\% - Rarely 31\% - Never 3\%

f Behavioural changes without physical changes

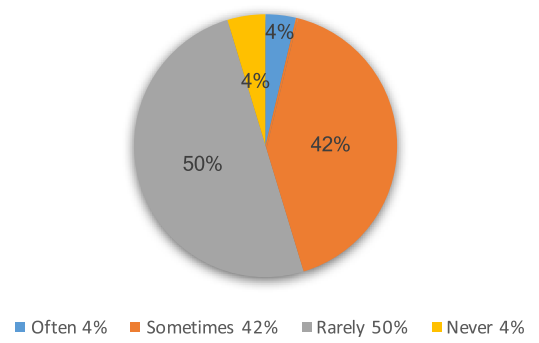

Fig. 4 Frequency of reported behavioural signs of pseudopregnancy in canines. a Collecting and mothering objects. b Nesting behaviour. c Increased activity. $\mathbf{d}$ Reduced activity. e Maternal aggression. $\mathbf{f}$ Behavioural changes without physical changes

Typically, when bitches presented with pseudopregnancy they were either not treated $(47 \%)$ or treated with cabergoline (48\%). The remainder were treated with proligestone (Delvosteron; Intervet, 2\%), megestrol (Ovarid; Jurox, $1 \%)$, and other (2\%, behavioural modification, diet or exercise). Behavioural modification, diet, and exercise were described as the sole treatment approach by vets in charity practices.

The mean number of days that cabergoline was prescribed was $5.7 \pm 0.1$ (median 5). Furthermore, 18\% of respondents reported that a repeated course of cabergoline was required to resolve behavioural signs and $68 \%$ respondents reported repeat courses were required for resolution of physical signs. The mean of longest number of days required for cabergoline to resolve both behavioural and physical signs was 13 days, although the range was bigger for resolution of physical signs (5-90 days compared to 6-42 days).

If a bitch presented for spaying and showed signs of pseudopregnancy, $96 \%$ of respondents would delay the procedure until the signs of overt pseudopregnancy had abated, whilst $4 \%$ of respondents would go ahead with the procedure regardless. Of those veterinary surgeons that would delay the procedure until physical and behavioural signs had resolved, 30\% would treat medically and $4 \%$ would treat with behavioural modification. The most commonly reported medical treatment was cabergoline at $93 \%$, followed by proligestone at $3 \%$. 


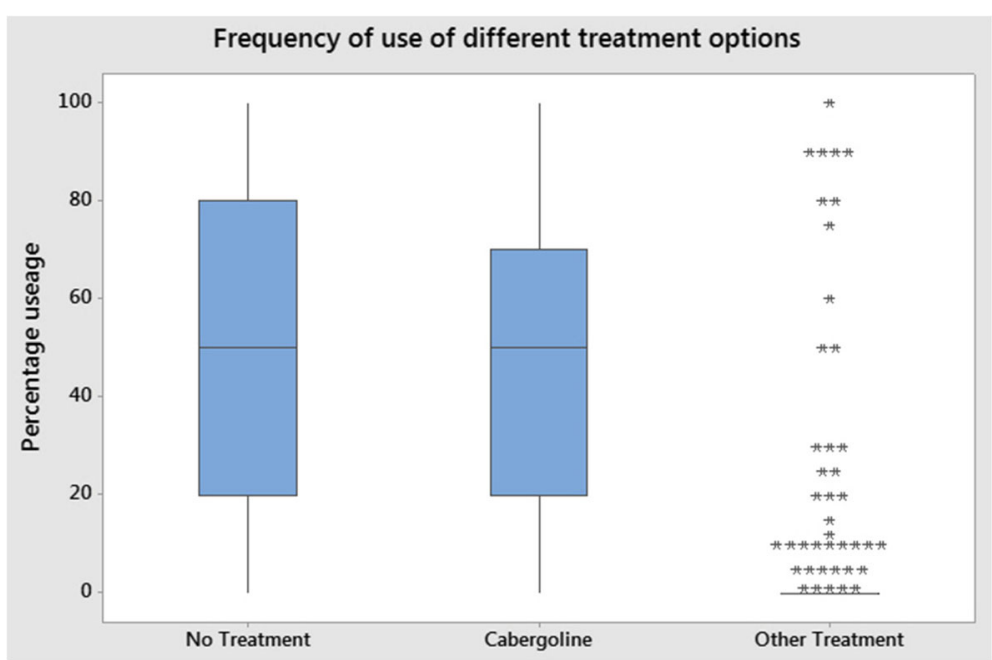

Fig. 5 Frequency of reported use of different treatment approaches in pseudopregnant bitches. Other treatments used were Megestrol (Ovarid; Jurox), Proligestone (Delvosteron; Intervet), antibiotics, behavioural modification, diet, and exercise

\section{Discussion}

This epidemiological study is the largest and first to assess presenting physical and behavioural signs of canine pseudopregnancy and the subsequent treatment choices made by practising veterinary surgeons in the UK. The exact incidence of clinical pseudopregnancy is not known, but has been estimated to be between 50 and $75 \%$ [5] and 10-20\% [14]. Mean prevalence of canine pseudopregnancy in the present study was 10 cases annually per vet and only $3 \%$ of veterinary surgeons did not encounter a case of pseudopregnancy in the previous year. If the survey population is representative of the total UK small animal practitioner population (10,022 on Vetfile database in June 2016), then approximately 100,000 cases of pseudopregnancy could occur annually (Personal communications with Market Research and Information Manager, Veterinary Business Development Ltd.).

Commonly measured reproductive hormones (prolactin and progesterone) clinically change in both the pregnant and overtly pseudopregnant bitch and cannot be reliably used as a diagnostic aid [1, 3, 4, 6, 10-13, 15]. Diagnosis of overt pseudopregnancy is usually based on timing of the onset of physical signs or behavioural

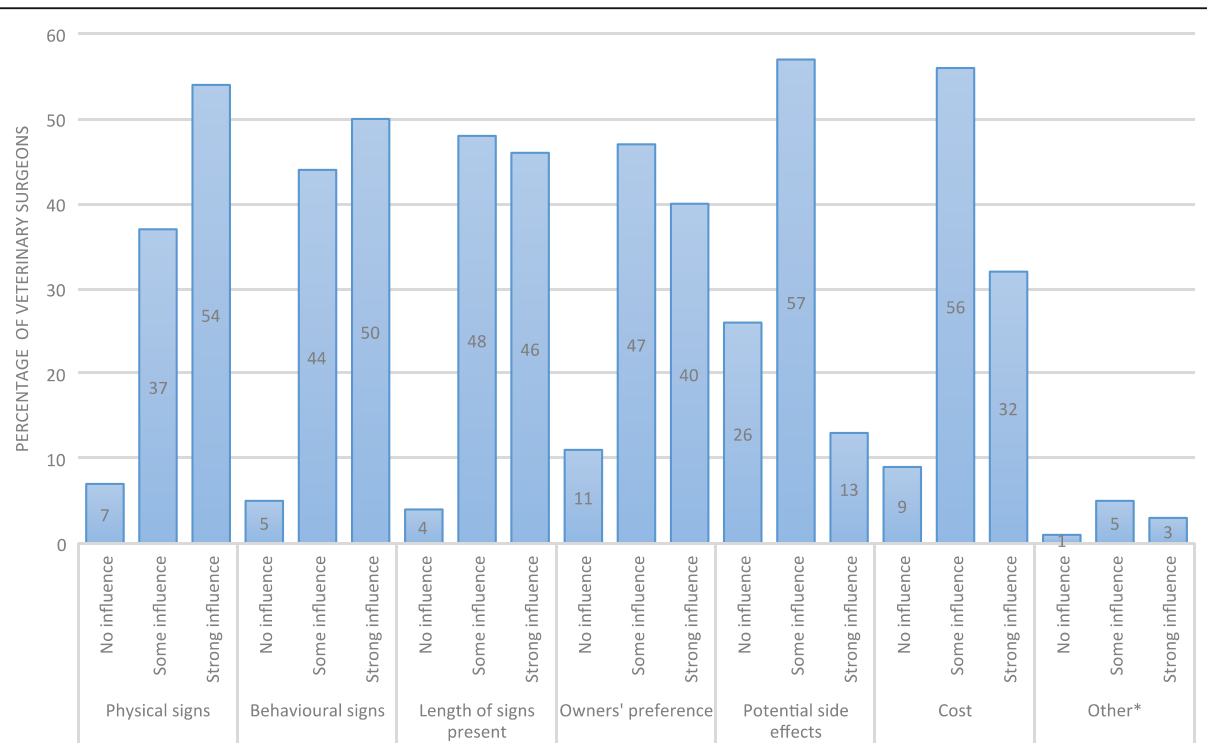

Fig. 6 Influence on treatment choices in pseudopregnant bitches. *Other influence on treatment approach reported were concurrent disease, drug availability, spaying, and previous history of pseudopregnancy. There were some missing responses for this question and not every veterinary surgeon treated all pseudopregnant bitches 
changes in relation to the previous season in entire bitches, or to being spayed, followed by a positive response to treatment with a prolactin-reducing drug, such as cabergoline. Other differential diagnoses, such as true pregnancy or pyometra, should be excluded $[3,15]$.

Of the physical signs reported in this study, mammary gland enlargement and/or milk production were the most frequent. Findings in the current study accorded with those of Harvey et al. in that some pseudopregnant bitches do not show physical signs at all [14, 16, 17]. In this current study, $96 \%$ of vets saw cases of pseudopregnancy presenting with behavioural signs alone in the preceding 12 months. The two most common behavioural signs reported were collecting and mothering objects and nesting behaviour and this is the first study to have reported frequency of these signs. It is possible that a significant proportion of cases of pseudopregnancy are undiagnosed particularly as a significant number of vets in practice did not routinely ask about behavioural changes during consultations; this has been previously reported [24, 25].

Moreover, in an epidemiological study of behavioural problems, Fatjo and colleagues reported that more than $75 \%$ of veterinary surgeons estimated that at least $10 \%$ of euthanasias were related to behavioural problems [26] and are associated with an increased risk of relinquishment to rehoming centres [24]. The current survey indicates that aggression is not uncommonly seen in pseudopregnant bitches; this is pertinent since it has serious implications for both owners and dogs $[9,25,29]$. Since only $52 \%$ of respondents often asked owners about behavioural changes during routine consultations, it suggests that there is significant room for improvement, especially for junior vets, who are less likely to ask about behavioural changes. Modification of risk factors for pseudopregnancy (i.e. being sexually intact), by spaying or pharmacological interventions, could reduce its frequency in entire bitches and sequentially reduce behavioural problems in dogs.

Veterinary literature proposes that the best preventive method for pseudopregnancy is to spay the bitch before the onset of first oestrous $[2,5,11,12,16,17,23]$, although there is some controversy over the behavioural and health-related effects of neutering before a season compared to after [32-36]. Otherwise, it is important to avoid spaying when a bitch has an overt pseudopregnancy or during the dioestral period $[2,5,6,11,12,14$, $17,30]$. Spaying during the dioestral period results in a rapid decline in plasma progesterone and a rise in plasma prolactin concentration. Pseudopregnancy can then become overt and possibly persistent, especially in bitches with a history of pseudopregnancy before they were spayed $[2,6,8,10-12,23,30]$.
This study indicated that $4 \%$ of vets would go ahead and spay a dog even when showing signs of pseudopregnancy, thus it is important that veterinary surgeons are educated and advised against doing so. Ideally, the entire overtly pseudopregnant bitch should be treated medically and the surgery delayed until clinical signs subside, or serum progesterone levels are tested or risk the persistence of clinical signs of pseudopregnancy $[6,16,23]$.

Since covert pseudopregnancy is a normal physiological condition, treatment is not required in many cases. However, treatment is warranted if physical or behavioural signs are extreme or last longer than 4 weeks, particularly if these are occurring in a bitch that has been spayed, otherwise signs might persist with each oestrous. Therefore, overt pseudopregnancy is a treatable condition with a good prognosis for resolution, as long as the underlying hormonal cause is recognised [10-12, 16, 37]. However, if under-recognised, as our data suggests, bitches may be treated inappropriately. Various classes of drugs have been specifically developed and used to treat pseudopregnancy, including anti-prolactins (Bromocriptine, Parlodel; Novartis, Cabergoline, Galastop; Ceva and Metergoline, Contralac; Virbac), progestogens (Proligestone, Delvosteron; Intervet and Megestrol, Ovarid; Jurox), serotonin agonists (Metergoline), and dopamine agonists (Bromocriptine and Cabergoline) $[1,2,11,12,15,37,38]$. Although, progestins were once widely used to treat overt pseudopregnancy in bitches, they are not fully effective because pseudopregnancy tends to recur once treatment is stopped and they have the potential to cause a wide range of serious side effects. Cabergoline is the suggested drug of choice for this condition, in part because it has the least side effects and longer duration of action $[1,11,12,15,16,23,37,39]$. However, although safe, cabergoline is an expensive drug. It is a selective prolactin inhibitor and effective in suppressing prolactin release from the pituitary $[1,4,23,38]$. It was the most commonly used drug in this study and $96 \%$ of vets reported prescribing it in the previous 12 months. The data showed cabergoline to be commonly prescribed for between five and 6 days. However, many vets in our study reported needing to use it for up to 13 days to resolve physical and behavioural signs of clinical pseudopregnancy. Ramsey states that cabergoline should be given for four to 6 days, but that control of aggression-related signs may require dosing for 14 days [38]. Bastan et al. used cabergoline in overtly pseudopregnant bitches and found that the enlarged mammary glands completely resolved by 7 days [1]. Some dogs $(68 \%, 260 /$ 397) required repeated courses of cabergoline to resolve physical signs completely, which compares to Harvey and colleagues, who found the overall success rate of pseudopregnant bitches using cabergoline for 5 days was 73\% (19/ 26) [23]. Cabergoline has been shown in many clinical studies to effectively reduce serum prolactin levels in 5 days 
$[1,16,39-41]$. Therefore, there should be improvement of clinical signs if pseudopregnancy is the correct diagnosis and there is not another cause of hyperprolactinaemia. As shown in this study, physical and behavioural signs took different lengths of time to resolve whether treatment was given or not. Of interest, was that up to 42 and 90 days of treatment were required for the behavioural and physical signs to disappear gradually, respectively. Whether physical signs are genuinely more difficult to resolve, or whether owners can 'accept' behavioural changes in their pets more readily than physical signs, or do not recognise the behavioural signs or other causes of clinical signs may be present, is open to debate and would require further investigation.

A minority of pseudopregnant bitches were treated by modification of behaviour, diet, and exercise. Specific behavioural management included, discouraging nesting and mothering behaviour, advising the owner to avoid touching or brushing the abdomen (i.e. specifically the mammary glands), and the application of an Elizabethan collar to reduce self-stimulation (e.g. licking) of the mammary glands, which could stimulate or perpetuate lactation. A range of factors were found to influence treatment choices, including physical and behavioural signs, duration of signs present, owners' preference, cost, concurrent disease, drug availability, spaying, and previous history of pseudopregnancy. Treatment options varied amongst vets, especially between junior and senior vets $(p<0.05)$, which indicated that there is individual clinical assessment and treatment judgement was tailored for each pet. This is shown by the broad interquartile ranges in the treatment choices in Fig. 5.

It is important to note that $39 \%$ of the respondents indicated willingness to participate in a future prospective study; certainly, there are more questions to be answered, such as asking veterinary surgeons how often pseudopregnant spayed bitches showed signs of pseudopregnancy before they were spayed, investigating the risk factors for pseudopregnancy in entire and spayed bitches, breed predisposition to pseudopregnancy, and how veterinary surgeons are currently diagnosing pseudopregnancy. Further education about this common disorder in dogs would be valuable to ensure optimal diagnosis and treatment strategies. There is an urgent requirement for robustly designed clinical trials along with diagnostic information on pseudopregnancy, since few diagnostic indicators have been consistent across studies due to the lack of standardisation and agreement of hormonal measurements.

\section{Limitations and strengths of study}

This study had a number of limitations that should be considered. This was a questionnaire-based study with a response rate of $19.8 \%$, so numbers were limited. For a postal survey, the response rate is considered low [42], therefore an inherent respondent bias cannot be excluded due to the small sample size. We were unable to conduct an assessment of non-responder bias due to the vast majority of respondents being anonymous. General practitioner veterinary surgeons were chosen as participants in this study due to their expected higher case load of pseudopregnancy. However, there may have been different results from diplomates as they may have additional expertise in diagnosing and treating pseudopregnancy in bitches. As a retrospective study, some of the answers were estimated rather than exact, which may have incurred errors since they were not directly observed from the veterinary surgeon. In addition, some of the answers were semi-quantitative.

Diagnosis of pseudopregnancy was based on clinical signs characterised by physical and/or behavioural changes commonly seen in veterinary medicine [3-6, $11-17,30]$. Diagnosis is not clear cut, is often a diagnosis of exclusion, and false negative or false positive diagnoses may be made. A final limitation is the lack of diagnostic data in this study, however there is a current lack of standardisation and the validity of such data is difficult to compare.

A strength of this study was that the respondent selection was random and geographically diverse, which represented a large sampling of different practices within the UK. Valuable information on presentation, diagnosis and clinical signs was gleaned and adds to our knowledge on canine pseudopregnancy in the UK. Additionally, this research produced empirical data based on real observations from a wide variety of owners and veterinary surgeons in practice, enhancing our depth of knowledge on the topic of canine pseudopregnancy.

\section{Conclusions}

This study was designed to evaluate different aspects of canine pseudopregnancy from the perspective of veterinary surgeons in general practice in the UK, since there is limited current data on the topic. Progress on our understanding of diagnosis and treatment of pseudopregnancy in spayed as well as entire bitches has been made. The main findings of the survey were that aggression is not uncommonly seen in pseudopregnant bitches, some covertly pseudopregnant bitches do not show obvious physical signs, pseudopregnancy can occur in spayed bitches, and not all vets routinely ask owners about behaviour during consultations. The prevalence and severity of clinical signs in dogs with pseudopregnancy in the UK seems to have been largely under-diagnosed in the past, since dogs with overt pseudopregnancy experience diverse physical and behavioural changes. The use of cabergoline has made a worldwide positive impact on the treatment of pseudopregnancy. Further, this study provided an estimate of the proportions of 
veterinary surgeons in the UK that see pseudopregnancy and common treatment protocols described. Clinicians should use their judgement for the most appropriate treatment plan for each patient. This study also highlights areas for future research; risk factors such as age, breed, parity, and environment have not been evaluated, frequency of post-spay pseudopregnancy in bitches, and how often this corresponds with aggressive behaviour also warrants investigation.

\section{Abbreviations}

Cl: Confidence intervals; UK: United Kingdom

\section{Acknowledgements}

The authors would like to thank the University of Glasgow, School of Veterinary Medicine and CEVA Animal Health LTD for providing funding for the study, Veterinary Business Development for sending out the questionnaires, and the veterinary surgeons for their participation.

\section{Funding}

Funding was obtained through the University of Glasgow, School of Veterinary Medicine and CEVA Animal Health LTD.

\section{Availability of data and materials}

The datasets used and/or analysed during the current study are available from the corresponding author on reasonable request.

\section{Authors' contributions}

AR performed the statistical analyses and drafted the manuscript. PY, CW, and $\mathrm{PH}$ contributed to the questionnaire design, study protocol, had input into the paper, reviewed results, and revised the draft manuscript. TP contributed to the questionnaire and study design, helped with statistical analysis, and revised the draft manuscript. All authors read and approved the final manuscript.

\section{Ethics approval and consent to participate}

This study was approved by the University of Glasgow's Research Ethics Committee under the reference $35 \mathrm{a} / 15$. Consent was implied if the participants responded to the survey.

\section{Competing interests}

AR's work was partially funded by CEVA Animal Health LTD.

\section{Publisher's Note}

Springer Nature remains neutral with regard to jurisdictional claims in published maps and institutional affiliations.

\author{
Author details \\ 'School of Veterinary Medicine, College of Medicine, Veterinary and Life \\ Sciences, University of Glasgow, 464 Bearsden Road, Glasgow G61 1QH, \\ Scotland. ${ }^{2}$ Good Companions, 3 The Hill, Bourton, Swindon SN6 8JA, \\ England.
}

Received: 1 February 2017 Accepted: 11 May 2018 Published online: 24 May 2018

\section{References}

1. Bastan A, Fmdik M, Erunal N, Asian S, Kiliçoğlu C. The use of cabergoline for treatment of pseudopregnancy in dogs with the purpose of suppressing lactation. Reprod Domest Anim. 1998;33:49-53.

2. Allen WE. Pseudopregnancy in the bitch: the current view on aetiology and treatment. J Small Anim Pract. 1986;27:419-24.

3. England GCW. Complications of treating presumed pseudopregnancy in pregnant bitches. Vet Rec. 1998;142:369-71.

4. Jöchle W. Prolactin in canine and feline reproduction. Reprod Domest Anim. 1997;32:183-93.

5. Johnston SD. False pregnancy in the bitch, Current vet Theriogenology 2nd ed. Philadelphia: WB Saunders Co; 1980. p. 623-4.
6. Lee WM, Kooistra HS, Mol JA, Dieleman SJ, Schaefers-Okkens AC. Ovariectomy during the luteal phase influences secretion of prolactin, growth hormone, and insulin-like growth factor-l in the bitch. Theriogenology. 2006;66:484-90.

7. Feldman EC, Nelson RW. Canine and feline endocrinology and reproduction: Breeding, pregnancy, and parturition. 3rd edition. St. Louis: WB Saunders Co; 2003:808-10.

8. Kooistra HS, Okkens AC. Secretion of prolactin and growth hormone in relation to ovarian activity in the dog. Reprod Domest Anim. 2001;36:115-9.

9. Kustritz MVR. Reproductive behavior of small animals. Theriogenology. 2005; 64:734-46.

10. England GC, Heimendahl AV. BSAVA manual of canine and feline reproduction and neonatology $2^{\text {nd }}$ edition. Cheltenham: British Small Animal Veterinary Association; 2010.

11. Gobello C, Concannon PW, Verstegen J: Canine pseudopregnancy: A Review. Recent advances in Small animal reproduction. Edited by: Concannon PW, England G, Verstegen J. 2011, Ithaca, New York USA Retrieved: International Veterinary Information Services, (www.ivis.org).

12. Gobello C, De La Sota RL, Goya RG. A review of canine pseudocyesis. Reprod Dom Anim. 2001;36:283-8.

13. Tsutsui T, Kirihara N, Hori T, Concannon PW. Plasma progesterone and prolactin concentrations in overtly pseudopregnant bitches: a clinical study. Theriogenology. 2007;67:1032-8.

14. Concannon PW. Reproductive cycles of the domestic bitch. Anim Reprod Sci. 2011;124:200-10.

15. Gobello C, De la Sota RL, Goya RG. Study of the change of prolactin and progesterone during dopaminergic agonist treatments in pseudopregnant bitches. Anim Reprod Sci. 2001;66:257-67.

16. Harvey MJ, Dale MJ, Lindley S, Waterston MM. A study of the aetiology of pseudopregnancy in the bitch and the effect of cabergoline therapy. Vet Rec. 1999;144:433-6.

17. Johnston SD. Pseudopregnancy in the bitch, Current vet Theriogenology 2nd ed. Philadelphia: WB Saunders Co; 1986. p. 490-1.

18. Luescher AU, Reisner IR. Canine aggression toward familiar people: a new look at an old problem. Vet Clin North Am Small Anim Pract. 2008;38:1 107-30.

19. Gobello C, Colombani M, Scaglia H, Rodolfo L, Goya RG. Heterogeneity of circulating prolactin in the bitch. Reprod Nutr Dev. 2001;41:505-11.

20. Gerres $\mathrm{S}$, Hoffmann B. Investigations on the role of progesterone in the endocrine control of overt pseudopregnancy in the bitch: application of an antigestagen and effects on corpus luteum function. Anim Reprod Sci. 1994;35:281-9.

21. Kim HH, Yeon SC, Houpt KA, Lee HC, Chang HH, Lee HJ. Effects of ovariohysterectomy on reactivity in German shepherd dogs. Vet J. 2006;172:154-9.

22. O'Farrell V, Peachey E. Behavioural effects of ovariohysterectomy on bitches. J Small Anim Pract. 1990;31:595-8.

23. Harvey MJ, Cauvin A, Dale M, Lindley S, Ballabio R. Effect and mechanisms of the anti-prolactin drug cabergoline on pseudopregnancy in the bitch. $J$ Small Anim Pract. 1997;38:336-9.

24. Patronek GJ, Glickman LT, Beck AM, McCabe GP, Ecker C. Risk factors for relinquishment of dogs to an animal shelter. J Am Vet Med Assoc 1996;209:572-81.

25. Roshier AL, MCBride EA. Canine behaviour problems: discussions between veterinarians and dog owners during annual booster consultations. Vet Rec. 2013;172:235.

26. Fatjo J, Ruiz-De-La-Torre JL, Manteca X. The epidemiology of behavioural problems in dogs and cats: a survey of veterinary practitioners. Anim Welfare-Potters Bar Wheathampstead. 2006;15:179.

27. Guy NC, Luescher UA, Dohoo SE, Spangler E, Miller JB, Dohoo IR, Bate LA. Demographic and aggressive characteristics of dogs in a general veterinary caseload. Appl Anim Behav Sci. 2001;74:15-28.

28. Landsberg GM, Hunthausen WL, Ackerman LJ. Behavior problems of the dog and cat: Canine aggression. 3rd edition. Edinburgh: Elsevier Health Sciences; 2012:385-426.

29. Mills DS. Current issues and research in veterinary behavioral medicine: papers presented at the fifth veterinary behavior meeting. West Lafayette: Purdue University Press; 2005.

30. Gobello C, Baschar H, Castex G, de la Sota RL, Goya RG. Dioestrous ovariectomy: a model to study the role of progesterone in the onset of canine pseudopregnancy. J Reprod Fertil Supp. 2001;57:55-60.

31. Wilson EB. Probable inference, the law of succession, and statistical inference. J Am Stat Assoc. 1927;22:209-12. 
32. Hart BL, Hart LA, Thigpen AP, Willits NH. Neutering of German shepherd dogs: associated joint disorders, cancers and urinary incontinence. Vet Med Sci. 2016;2:191-9.

33. Overall KL, Beebe AD. Dominance aggression in young female dogs: what does this suggest about the heterogeneity of the disorder. In: European Society of Veterinary Clinical Ethology: Proceedings of the First International Conference on Veterinary Behavioural Medicine. 1997;1:58-63.

34. Torres de la Riva G, Hart BL, Farver TB, Oberbauer AM, LLM M, Willits N, Hart LA. Neutering dogs: effects on joint disorders and cancers in golden retrievers. PLoS One. 2013;8:e55937.

35. Zink MC, Farhoody P, Elser SE, Ruffini LD, Gibbons TA, Rieger RH. Evaluation of the risk and age of onset of cancer and behavioral disorders in gonadectomized Vizslas. J Am Vet Med Assoc. 2014;244:309-19.

36. Kustritz MVR. Determining the optimal age for gonadectomy of dogs and cats. J Am Vet Med Assoc. 2007:231:1665-75.

37. Gobello C. Dopamine agonists, anti-progestins, anti-androgens, long-term release $\mathrm{GnRH}$ agonists and anti-estrogens in canine reproduction: a review. Theriogenology. 2006;66:1560-7.

38. Ramsey I. BSAVA small animal formulary $9^{\text {th }}$ edition: part A- canine and feline. Quedgeley: British Small Animal Veterinary Association; 2017.

39. Arbeiter K, Brass W, Ballabio R, Jöchle W. Treatment of pseudopregnancy in the bitch with cabergoline, an ergoline derivative. J Small Anim Pract. 1988;29:781-8.

40. Onclin K, Verstegen JP. In vivo investigation of luteal function in dogs: effects of cabergoline, a dopamine agonist, and prolactin on progesterone secretion during mid-pregnancy and-diestrus. Domest Anim Endocrinol. 1997;14:25-38.

41. Verstegen JP, Onclin K, Silva LD, Concannon PW. Effect of stage of anestrus on the induction of estrus by the dopamine agonist cabergoline in dogs. Theriogenology. 1999;51:597-611.

42. Sitzia J, Wood N. Response rate in patient satisfaction research: an analysis of 210 published studies. Internat J Qual Health Care. 1998;10:311-31.

\section{Ready to submit your research? Choose BMC and benefit from:}

- fast, convenient online submission

- thorough peer review by experienced researchers in your field

- rapid publication on acceptance

- support for research data, including large and complex data types

- gold Open Access which fosters wider collaboration and increased citations

- maximum visibility for your research: over $100 \mathrm{M}$ website views per year 